\title{
CONTRIBUIÇÕES DA ANÁLISE DO DISCURSO PARA O ENSINO DE LEITURA: O CONCEITO DE INTERDISCURSO
}

\author{
Contributions of Discourse Analysis to the teaching of reading: \\ the concept of interdiscourse
}

\author{
Karla Maria Marques PEIXOTO \\ Universidade Estadual do Piauí \\ karlammarques@gmail.com \\ https://orcid.org/0000-0001-5641-1237 \\ Mônica de Souza SERAFIM \\ Universidade Federal do Ceará \\ mserafim15@gmail.com \\ https://orcid.org/0000-0003-1518-3009
}

\begin{abstract}
RESUMO: O presente artigo tem como objetivo central relacionar a noção de interdiscurso ao ensino de leitura, revisitando conceitos que sustentam as bases teóricas da Análise do Discurso, além de realizar uma transposição didática para o ensino de leitura, seguindo as etapas de uma aula pautada na concepção sociopsicolinguística de leitura (BRAGGIO, 1992). Para tanto, basear-nos-emos no quadro teórico da Análise do Discurso de orientação francesa com o intuito de realizar a análise de um cartoon e de uma peça publicitária, e, posteriormente, propor questões de leitura que tenham como entrada no texto o conceito de interdiscurso (MAINGUENEAU, 1997), (CHARADEAU; MAINGUENEAU, 2008). As reflexões traçadas nesse estudo demonstram que a Análise do Discurso pode contribuir para a formação de leitores críticos na medida em que essa área do conhecimento nos proporciona dispositivos de análise que nos possibilita trazer à tona reflexões que ultrapassem o limite da superfície textual.
\end{abstract}

PALAVRAS-CHAVE: Análise do Discurso; Interdiscurso; Ensino de Leitura.

\begin{abstract}
The main objective of this article is to relate the notion of interdiscourse to the teaching of reading, revisiting concepts that support the theoretical bases of Discourse Analysis, in addition to carrying out a didactic transposition into the teaching of reading, following the steps of a class based on the conception socio psycholinguistics (BRAGGIO, 1992). To do so, we anchored ourselves to the theoretical framework of Discourse Analysis of French orientation in order to carry out the analysis of a cartoon and an advertising piece, and, later, to propose reading questions that have the concept of interdiscourse as input in the
\end{abstract}


text. (MAINGUENEAU, 1997); (CHARADEAU; MAINGUENEAU, 2008). The reflections traced in this study demonstrate that Discourse Analysis can contribute to the formation of critical readers to the extent that this area of knowledge provides us with analytical devices that allow us to bring up reflections that go beyond the limit of the textual surface.

KEYWORDS: Discourse Analysis; Interdiscourse; Reading Teaching.

\section{INTRODUÇÃO}

A linguagem é uma atividade que consiste, em todas as suas dimensões, numa dinâmica interativa, em que cada elemento ou ação é marcado pela presença irredutível e, por vezes, conflituosa do outro. O signo, enquanto objeto significativo mínimo dessa atividade, é visto como signo ideológico, isto é, como necessariamente já habitado por outros pontos de vista, mas também e, consequentemente, de significação sempre inacabada e, por isso, sempre sujeita a disputa pelas forças sociais que o utilizam, atuando a partir de um princípio regulador da produtividade na visão social, relacionado a sujeitos sociais e culturalmente construídos.

Como elemento de mediação necessária entre o homem e sua realidade e como forma de engajá-lo na própria realidade, a linguagem, para a Análise do Discurso - AD - é lugar de conflito, de confronto ideológico, não podendo ser estudada fora da sociedade. A linguagem enquanto discurso não constitui um universo de signos que serve apenas como instrumento de comunicação ou suporte para representar o pensamento, ela é interação e um modo de produção social; ela não é neutra, inocente e, por isso, é o lugar privilegiado de manifestação da ideologia (ORLANDI, 2005).

Entendemos que há uma certa hegemonia, no Brasil, no campo das pesquisas em Linguística Aplicada e em Didática de Línguas sobre as problemáticas e os dilemas referentes aos processos de ensino-aprendizagem nas áreas relacionadas à linguagem. Temos consciência de que a Linguística Aplicada não é uma aplicação de teorias linguísticas, visando o aprimoramento de técnicas ou metodologias de sala de aula, ou mesmo propostas de como ensinar uma língua, interesse esse mais pertinente a uma Didática de Línguas.

Apesar da predominância dessas áreas da Linguística ao tomar o contexto do ensino-aprendizagem como objeto de estudo e intervenção, compreendemos que os 
conceitos provenientes da $\mathrm{AD}$, área na qual esse artigo se inscreve, podem trazer contribuições para o processo de ensino-aprendizagem de língua materna, no sentido de instrumentalizar o professor com procedimentos didáticos que possam desenvolver a competência discursiva nos alunos.

Os aportes teóricos provenientes da Análise do Discurso criaram dispositivos de análise que nos possibilitam acessar a dimensão ideológica e conflituosa da linguagem materializada nos textos. Diante disso, no presente estudo, almejamos demonstrar algumas possíveis contribuições da Análise do Discurso para o ensino de leitura, propondo como entrada no texto a noção de interdiscurso, tendo em vista uma concepção dialógica de texto, ou seja, compreendendo-o como o lugar de constituição e de interação de sujeitos sociais.

A Base Nacional Comum Curricular (BNCC), assim como os Parâmetros Curriculares Nacionais (PCN), assumem a concepção enunciativo-discursiva de linguagem para prescrever as competências e as habilidades que devem ser trabalhadas na disciplina de Língua Portuguesa. Percebe-se, portanto, que, ao menos do ponto de vista institucional, se reconhece a necessidade de se estabelecer uma relação entre a $\mathrm{AD}$ e o ensino de língua portuguesa.

Apesar dos estudos da AD já terem se propagado pelo Brasil, desde os anos 1960, e do reconhecimento institucional que essa área do conhecimento possui, ainda é comum se identificar práticas em sala de aula que só reconhecem a função instrumental da linguagem, mantendo a noção de que ensinar uma língua é apenas dotar o aluno com regras específicas para que ela funcione como um instrumento efetivo de comunicação. Com essa afirmação, não estamos negando o caráter instrumental da linguagem, mas acreditamos que devem ser adotadas concepções teóricas e procedimentos didáticos que possam trabalhar essa dimensão conflituosa e ideológica da linguagem cujas noções são provenientes da $\mathrm{AD}$.

Fundamentada em estudos discursivos sobre aulas de língua materna e estrangeira, que tomam textos como objeto de estudo, Coracini (1995) indica que o texto constitui, na escola, o lugar instituído do saber, funcionando, pedagogicamente, como objeto onde se inscreve, objetivamente a verdade, que parece atemporal e definitiva que deve ser decifrada e assimilada pelo aluno. As considerações da autora indicam que o leitor é 
frequentemente silenciado em sua condição de intérprete, pois raramente é dada a ele a oportunidade para se posicionar criticamente em relação ao material lido.

Dessa forma, torna-se relevante ressaltar a necessidade de uma renovação do ensino de leitura que se configure em uma prática que priorize o pensamento crítico e as habilidades argumentativas, permitindo uma leitura crítica, transformadora, pautada no desenvolvimento de potencialidades, contribuindo com a formação de sujeitos autônomos, críticos, capazes de se valerem, estrategicamente, dos mecanismos discursivos em prol de sua prática cidadã.

Para demonstrar as contribuições que a $\mathrm{AD}$ pode trazer para o ensino de leitura, exporemos, primeiramente, alguns conceitos relevantes para essa área do conhecimento, teceremos considerações acerca dos conceitos de texto e discurso, trataremos sobre a noção de dialogismo, intertextualidade e interdiscurso e, por fim, analisaremos um cartoon e uma peça publicitária, propondo algumas questões cuja entrada no texto parte do conceito de interdiscurso. Estes materiais foram escolhidos de dois sites por conjugarem as três noções apresentadas, a saber, o dialogismo, a intertextualidade e o interdiscurso e também pela temática que estes apresentam: o empoderamento feminino. Tal temática se faz cada vez mais necessária a ser trabalhada com os jovens, pois ajuda na promoção da igualdade de gênero, na diminuição do machismo e na construção de uma vida com menos desigualdades (BRASIL, 2013).

\section{ANÁLISE DO DISCURSO: UMA COMPLEXA TRAMA DE TEORIAS}

A Análise do Discurso configura-se como uma área do conhecimento de cunho interdisciplinar que trouxe à tona o conceito de significação social da linguagem, envolvendo aspectos da Linguística (como base sistemática), do Materialismo Histórico (como base da inscrição material da história na língua) e da Psicanálise (como referencial para a noção de sujeito).

Herdeira dessas três áreas do conhecimento, a $\mathrm{AD}$ não as trabalha de forma autônoma, buscando entrever as lacunas deixadas por elas no que se refere à determinação histórica dos processos semânticos. Nessa perspectiva, no momento da sua formação, lança o questionamento à Linguística de orientação estruturalista quanto à historicidade constitutiva da linguagem que era relegada por ela; indaga ao Materialismo Histórico 
quanto às questões relacionadas ao simbólico e à Psicanálise pelo modo como, considerando a historicidade, deve-se conceber a ideologia como materialmente relacionada ao inconsciente (ORLANDI, 2005).

O princípio teórico fundamental para a $\mathrm{AD}$ é a consideração de que há uma relação inextrincável entre linguagem e exterioridade, e, desse modo, procura compreender a maneira como um objeto simbólico produz sentidos, não a partir de um gesto automático de decodificação, mas como um procedimento que desvenda a historicidade contida na linguagem.

A fundação da Análise do Discurso de orientação francesa, proposta por Michel Pêcheux, no final dos anos 1960, tratava-se de uma ruptura com a análise de conteúdo, a qual, por sua vez, buscava responder a perguntas como $O$ que quer dizer esse texto?, ou Que significação contém esse texto?, para passar a abordar um funcionamento do texto relacionado ao fato de que, se tomado como discurso, ele é sempre produzido a partir de condições de produção dadas e situa-se no interior de relações de forças existentes entre os elementos antagonistas de um campo político dado. A AD, ao romper com a análise de conteúdo, compreende o discurso como o lugar privilegiado que materializa a ideologia, trabalhando com o sentido e não com o conteúdo do texto em si.

Conforme Maingueneau (1997), o objeto da Análise do Discurso não se reduz aos aspectos da organização textual tampouco à situação de comunicação, mas funciona a partir da intercessão entre essas duas instâncias através de um modo de organização específico. A maneira como um determinado discurso interage por meio de um texto e de um lugar social é o ponto fulcral dessa disciplina. Ainda na esteira da delimitação do objeto de estudo da $\mathrm{AD}$, no que se refere aos dispositivos enunciativos, é importante ressaltar a relação intrínseca entre o verbal e o institucional, na medida em que conceber os lugares sociais de forma independente do simbólico, que os torna possíveis, e pensar o simbólico desassociado dos lugares sociais que os constitui seria ficar aquém das exigências seminais que fundam a área do conhecimento em questão.

Nessa perspectiva, o analista do discurso precisa demonstrar em suas análises o caráter central da noção de gênero do discurso que, por sua vez, deve ser pensado na perspectiva da instituição discursiva para não correr o risco de tecer considerações simplistas entre texto e contexto. 
A língua, no campo da Análise do Discurso, diverge da concepção saussuriana, não sendo considerada como um sistema, excedendo os limites da Linguística Estruturalista, pois não considera a língua como uma instância transparente, autônoma e marcada pela imanência, mas sim a língua da ordem material, da opacidade, da possibilidade do equívoco como fato estruturante, da marca da historicidade inscrita na língua. É a língua da indefinição do direito ao avesso, do dentro e fora, da presença e ausência (FERREIRA, 2003, p. 43).

Ao considerar a relação entre linguagem e historicidade, a Análise do Discurso pode constituir-se como um valioso aporte teórico no sentido de instrumentalizar o professor a conduzir um projeto de ensino que considere a formação de leitores que sejam capazes de interpretar as nuances que se encontram materializadas no texto, ao possibilitar o reconhecimento das marcas estruturais e ideológicas, revelando a historicidade que lhes é constitutiva.

Conforme já mencionamos, temos o objetivo de demonstrar algumas contribuições da Análise do Discurso para o ensino de leitura, propondo como entrada no texto o conceito de interdiscurso, realizando a análise de uma peça publicitária e de um cartoon. Tendo em vista este objetivo e dando prosseguimento ao percurso teórico traçado para este estudo, trataremos na próxima seção sobre a noção de dialogismo, concepção basilar para a compreensão da categoria selecionada por nós, no caso, o interdiscurso.

\section{AS NOÇÕES DE TEXTO E DISCURSO E O ENSINO DE LEITURA}

Muitos estudiosos da linguagem, principalmente os que se ocupam da Linguística de Texto mais clássica, não fazem a distinção entre texto e discurso. No entanto, a maioria dos linguistas fazem essa distinção, que é, a nosso ver, bastante produtiva para o ensino de leitura. É importante, portanto, que o professor de língua portuguesa tenha acesso e reconheça essa distinção para que ele possa realizar um trabalho de transposição didática dessas teorias na medida em que tomar apenas os aspectos linguísticos e as relações cotextuais como objeto de ensino não dão conta de explicar todos os fenômenos reais de linguagem que são produtos da enunciação.

Nesse sentido, a título de exemplificação, para compreendermos os efeitos de sentido de um texto mesmo curto como "É proibida a entrada de pessoas não autorizadas", 
afixado na porta de uma delegacia, é preciso ter acesso aos conhecimentos linguístico, enciclopédico e interacional mobilizados para a construção desse enunciado, desde o estabelecimento de regras morfossintáticas acionadas para a construção de sintagmas possíveis em língua portuguesa ao estabelecimento de regras semânticas e pragmáticas mobilizadas para que o texto faça sentido.

Além dos aspectos linguísticos, enciclopédico e interacional envolvidos na construção do texto, ele só produz os efeitos de sentidos esperados quando o leitor compreende o enunciado de maneira situada, ou seja, envolvendo-se no jogo de linguagem que reconhece as regras coletivas sócio-historicamente construídas para que essa atividade de linguagem faça sentido. Dessa maneira, compreender o conceito do que é proibição, compreender quem pode proibir, quem deve ser proibido, bem como as punições do não cumprimento da proibição são aspectos tão pertinentes para a compreensão do enunciado quanto os envolvidos na construção linguística.

Tanto texto como discurso são um todo organizado de sentido, pois tanto um quanto o outro supõem uma organização transfrástica, o que significa que mesmo quando o discurso tem a dimensão de uma frase, ele mobiliza estruturas de ordem diferente das da frase, mas há diferenças entre texto e discurso, uma vez que o primeiro é da ordem da manifestação e o segundo do domínio da imanência (FIORIN, 2012).

O termo manifestação é tomado na acepção de presentificação da forma em uma dada substância, o que significa que o discurso é do plano do conteúdo, ao passo que o texto é do plano da expressão. O texto é a manifestação do discurso, o texto pressupõe logicamente um discurso que o sustenta, sendo anterior a ele.

Teorias do texto levam em conta os conhecimentos prévios dos locutores e compartilhados entre interlocutores, mas os consideram em um quadro que supõe, exatamente, o leitor/ouvinte como suporte de conhecimento como o agente que assim produz a coerência do texto (MARCUSCHI, 2008). Para a AD, ao contrário, um texto faz sentido não por sua relação com um contexto ou em decorrência de conhecimentos que o leitor tenha estocado ou que rememora e coloca em funcionamento ao ler/ouvir, mas por sua inserção em uma formação discursiva, em função de uma memória discursiva, do interdiscurso, que o texto remonta e do qual é parte, ou seja, não há propriamente texto, concebido como uma unidade, o que há são linearizações concretas de discursos. 
As formações discursivas são definidas por Foucault (1996) como um conjunto anônimo de regras construídas historicamente e sempre determinadas no tempo e no espaço e que definem as condições de exercício da função enunciativa em uma dada área social, econômica, geográfica ou linguística. Nessa perspectiva, a noção de formação discursiva permite designar todo o conjunto de enunciados sócio-historicamente circunscrito que pode relacionar-se a uma identidade enunciativa como, por exemplo, o discurso comunista, o conjunto de discursos proferidos por uma administração, os enunciados que decorrem de uma ciência dada, o discurso de um determinado partido político e o discurso religioso, etc.

De acordo com Pêcheux (1998; 2006), um sujeito enuncia a partir de um lugar social, sendo o seu dizer atravessado pela ideologia inerente a esse lugar social, veiculando os sentidos que têm traços enunciativos específicos a ela. Os sujeitos, no entanto, são advindos de vários lugares sociais, carregando no seu dizer os traços enunciativos da formação discursiva referente a esse lugar. As formações discursivas, por sua vez, são heterogêneas, pois o sentido delas se constrói na dependência com o interdiscurso, ou seja, nos discursos que vêm de vários lugares sociais e se entrecruzam. Essa acepção de interdiscurso será a adotada nesse texto, uma vez que precisamos, para fins escolares, tentar ao máximo possível materializar essa categoria de análise de textos. Sendo assim, analisaremos os lugares sociais de onde o enunciador fala, o lugar social de onde os co-enunciadores, no caso os alunos, falam e os discursos que entrecruzam os textos e os sujeitos.

Fiorin (2007) concebe ideologia como o conjunto de ideias e representações que servem para justificar e explicar a ordem social, as condições de vida do homem e as relações que ela mantém com outros homens. Nessa perspectiva, a noção de formação ideológica vincula-se à visão de mundo de um determinado grupo social. Já as formações discursivas, construídas ao longo do processo de aprendizagem linguística, correspondem, por sua vez, ao conjunto de enunciados que materializam uma dada visão de mundo, ou seja, as formações discursivas constituem o conjunto de enunciados marcados pelas mesmas regras de formação.

É importante destacar que a cada formação ideológica corresponde uma formação discursiva, uma vez que os textos que constituem uma determinada formação discursiva 
remetem a uma mesma formação ideológica. O discurso, considerado enquanto um construto social é, primeiramente, o lugar da apropriação antes de o ser da criação, pois ele materializa as formações ideológicas interiorizadas pelos indivíduos no decorrer da sua vida que, por sua vez, se constroem a partir de relações interdiscursivas. Assim, na medida em que é determinado pelas formações ideológicas, o discurso cita outros discursos (FIORIN, 2007, p. 41).

Ao tomarmos a dimensão discursiva, materializada no texto, como objeto de ensino, podemos ter acesso a essas formações discursivas que dizem respeito à existência histórica do enunciado, fazendo com que os educandos acessem aos posicionamentos políticos e ideológicos que não são construídos de forma individual, pois estão organizados em formações que mantêm entre si relações de antagonismo, de aliança, de relativismo ou de dominação.

Para compreendermos a noção de interdiscurso, a qual guiará as nossas análises, é importante tratar sobre a noção de dialogismo bakhtiniano que está na base da sua formação. Na próxima seção, trataremos sobre a dimensão dialógica da linguagem que atravessa os conceitos de intertextualidade e interdiscursividade.

\section{DIMENSÃO DIALÓGICA DA LINGUAGEM, INTERTEXTUALIDADE E INTER- DISCURSIVIDADE}

O termo dialogismo remete, evidentemente, ao diálogo em que necessariamente há a presença irredutível do outro. Para a perspectiva bakhtiniana, a linguagem é um fenômeno essencialmente dialógico, ou seja, consiste em uma atividade que, em todas as suas dimensões, se configura a partir de uma dinâmica interativa, em que cada elemento ou ação é marcado pela presença irredutível e, por vezes, conflituosa da subjetividade e da alteridade. A perspectiva dialógica da linguagem configura-se a partir da concepção de língua como interação verbal em que os interlocutores são marcados social, ideológica e historicamente.

No entanto, a perspectiva dialógica da linguagem não se resume apenas a presença do autor e do enunciador na interação, pois concebe que em todo ato de enunciação entram em cena diversas vozes, podendo também ser chamadas de discursos, cuja presença pode ser marcada de forma explícita ou não. Pode-se afirmar que o dialogismo funciona como 
uma espécie de axioma que atravessa diferentes aspectos das teorias relacionadas ao discurso. Tal axioma coloca a enunciação como o centro de referência dos fenômenos linguísticos, o evento que institui o sujeito na interação viva com as vozes sociais, não concebendo o estudo da língua a não ser na enunciação.

Conforme expressa Bakhtin (1992), as relações dialógicas não ocorrem a partir dos elementos do sistema linguístico considerados somente de maneira autônoma, tanto a partir das palavras em si como também dos próprios elementos que compõem os textos, pois as relações dialógicas possuem um caráter essencialmente extralinguístico, ao mesmo tempo em que não podem ser desassociadas do campo discursivo, ou seja, dos elementos linguísticos. Para os estudos discursivos, ao analisar um texto como enunciados concretos, é necessário considerar a posição social, histórica e ideológica dos interlocutores, além de verificar as condições de produção dessa interação e os demais discursos que entram em relação dialógica com o enunciado.

O signo, enquanto objeto significativo mínimo de todos os enunciados, é visto como ideológico, isto é, como necessariamente já habitado por outros pontos de vista, mas também e, consequentemente, de significação sempre inacabada e, por isso, sempre sujeito à disputa pelas forças sociais que o utilizam. O signo ideológico disputa um território onde confrontam-se índices de valor contraditórios. A consequência dessa associação será uma concepção semiótico-ideológica de texto em que essas dimensões, semiótica e ideológica, funcionam como um princípio regulador da produtividade na visão social, relacionado a sujeitos social e culturalmente construídos.

Ainda na esteira do entendimento da concepção dialógica da linguagem, o texto, enquanto construto histórico e social, é lugar de interação entre sujeitos sociais que se constituem na sua relação com os outros, das palavras dos outros, pois tudo o que pertence à consciência chega a ela através da palavra do outro. O sujeito não é autônomo, nem cuidador da sua própria linguagem, ao contrário, ele se constitui na relação com os outros indivíduos que é atravessado por diferentes usos da linguagem de acordo com a esfera social na qual ele se inscreve.

A dimensão dialógica da linguagem também é constitutiva dos discursos, na medida em que um discurso legitima a sua identidade somente quando posto em relação com outros discursos que ele cita, parodia, estiliza, relativiza, etc. Em termos de gênese, os 
discursos não se constroem independentes uns dos outros para somente depois serem postos em relação, uma vez que eles se originam de maneira regulada no interior do interdiscurso. Nessa perspectiva, pode-se considerar que todo discurso é atravessado pela interdiscursividade, tem a propriedade de estar em relação multiforme com outros discursos (FIORIN, 2012).

Por serem dialógicos é que os discursos são objetos históricos, mas essa historicidade não pode ser considerada como produto de fatos externos que têm como referência certos acontecimentos de uma época. Ela é captada no próprio movimento semiótico e interdiscursivo da sua constituição, pois é na percepção que perpassa os discursos dos outros a partir de reprovações, aprovações, polêmicas, adesões e recusas que se constitui essa historicidade.

De acordo com Fiorin (2012), como o texto é uma unidade de manifestação do discurso, não é necessário que ele mantenha necessariamente relações dialógicas com outros textos, não sendo, portanto, a intertextualidade uma relação necessária, porém possível. Assim, denomina-se intertextualidade os casos em que a relação entre discursos é materializada em textos. Isso significa que a intertextualidade pressupõe sempre uma interdiscursividade, mas que o contrário não é verdadeiro.

Quando a relação dialógica não se manifesta no texto, temos interdiscursividade, mas não intertextualidade. No entanto, é preciso verificar que nem todas as relações dialógicas no texto devem ser consideradas intertextuais. A intertextualidade diz respeito à relação entre mais de um texto, pois ocorre quando um texto se relaciona dialogicamente com outro texto já construído, quando um texto se encontra com outro, quando duas materialidades se cruzam, quando duas manifestações discursivas se atravessam.

O dialogismo bakhtiniano, ao conceber a linguagem como uma atividade humana constitutivamente heterogênea, interativa, social e plurilinguística em que a relação com o outro é a base da discursividade, abre um horizonte teórico fundador para diversos outros desenvolvimentos teóricos. Ao se pensar em uma competência discursiva para o ensino de leitura, focalizada neste artigo, temos a consciência da necessidade e do desafio de mostrar caminhos para que o professor aborde os diversos gêneros do discurso a partir dessa perspectiva, fazendo com que o aluno perceba que os discursos se constroem para além dos textos particulares nos quais eles se manifestam, uma vez que os discursos são 
construídos coletivamente a partir do movimento das relações interdiscursivas.

\section{O INTERDISCURSO}

A noção de interdiscurso, sob diversas nomenclaturas (polifonia, dialogismo, heterogeneidade, intertextualidade) cada uma atravessando um viés específico, foi fundada a partir do dialogismo bakhtiniano. Essa categoria discursiva emprega que o discurso só ganha sentido e identidade na relação com outros discursos que ele cita, parodia, estiliza, concorda, discorda, etc. Em termos de gênese, os discursos não se constroem independentes uns dos outros, para depois serem postos em relação, se constituindo de maneira regulada no interior do interdiscurso. Todo discurso é atravessado pela interdiscursividade, uma vez que tem a propriedade de estar em relação multiforme com outros discursos.

Em Charaudeau e Maingueneau (2008), o verbete interdiscurso é apresentado em dois sentidos: em um sentido restritivo, cuja formulação concebe que os discursos do mesmo campo se delimitam reciprocamente uns aos outros, e com um sentido mais amplo, que o considera a partir do apanhado das unidades discursivas com as quais um discurso entra em relação explícita ou implícita. No mesmo verbete, os autores também tratam sobre o primado do interdiscurso, o qual consideram uma formação discursiva como uma instância que produz o assujeitamento do sujeito, uma vez que, sendo uma formação discursiva dominada pelo interdiscurso, ela exclui a possibilidade de contrastar formações discursivas consideradas independentemente umas das outras.

De acordo com Maingueneau (1997), há uma tríade conceitual que se relaciona quando se pensa em interdiscurso e formações discursivas, a saber: universo discursivo, campo discursivo e espaço discursivo. No universo discursivo, tem-se um conjunto de formações discursivas interagindo em uma dada conjuntura, sendo constituído por diversos campos: o político, o científico, o religioso, o filosófico, etc. Os campos discursivos constituem o conjunto de formações discursivas que se encontram em concorrência, seja em confronto aberto, em aliança, na forma de neutralidade aparente e delimitam-se reciprocamente numa região determinada do universo discursivo. Cada campo discursivo é, de forma dialética, constituído de vários espaços discursivos. Quanto aos espaços discursivos, são considerados como os subconjuntos de formações discursivas 
selecionadas pelo próprio analista para serem colocadas em relação, de acordo com o seu propósito.

O autor supracitado também destaca a dimensão polêmica que caracteriza o campo discursivo. Nesse sentido, as polêmicas em que as formações discursivas estão envolvidas são a própria atualização do processo de delimitação recíproca que as constitui. Nessa perspectiva, partindo de um enunciado como "Lugar de mulher é onde ela quiser" há uma série de forças ideológicas que atravessam esse enunciado, estando associadas à formação discursiva específica que, no caso, são os posicionamentos do feminismo que emprega a igualdade de direitos entre homens e mulheres, encontrando-se em oposição aos posicionamentos advindo da formação discursiva do patriarcado, que prevê o cerceamento de liberdades às mulheres.

Para Análise do Discurso de matriz francesa, de base pecheutiana, isto é, a que está fortemente baseada em uma perspectiva materialista histórica da linguagem, interdiscurso é uma noção-conceito analisável, uma vez que em todo discurso é possível se reconhecer o interdiscurso como "o complexo dominante" (PEUCHÊX, 2006). Ou seja, o interdiscurso é um pressuposto teórico básico para se entender um discurso em relação a outro discurso. Desse modo, o interdiscurso, assim como o intradiscurso, é aquilo que engendra todo o método discursivo de compreensão dos objetos do discurso a serem descritos, analisados e interpretados.

A AD contribui para pensar o ensino de leitura na perspectiva de formação de um leitor crítico, pois se trabalha na ótica de que o discurso se constitui nas relações estabelecidas com os outros discursos, mostrando que os sentidos estão sempre à deriva, pois podem ser compreendidos a partir da identificação das formações discursivas que estão em jogo. Ao considerarmos todos estes conceitos advindos da $\mathrm{AD}$, torna-se possível afirmar que a noção de interdiscurso funciona como elemento de reconhecimento ideológico. Conceber as relações interdiscursivas como objeto de ensino é trabalhar a dimensão conflituosa, opaca e polêmica materializadas em um dado texto, seja ele escrito, falado ou imagético. É também buscar entender o texto enquanto um objeto linguísticohistórico e como ele materializa a interdiscursividade que o constitui.

$\mathrm{Na}$ próxima seção do nosso texto, apresentaremos uma atividade de leitura, propondo como entrada no texto o conceito de interdiscurso, a partir da análise de um 
cartoon e de uma peça publicitária.

\section{A NOÇÃO DE INTERDISCURSO COMO UMA POSSÍVEL ENTRADA DISCURSIVA NA AULA DE LEITURA}

Conforme já mencionamos, os conceitos construídos a partir dos estudos da Análise do Discurso nos possibilitam acessar a dimensão ideológica e conflituosa da linguagem materializada nos textos a partir dos seus dispositivos de análise. Levando em consideração a necessidade de construir um ensino de língua portuguesa que esteja pautado também na dimensão discursiva da linguagem, e não somente a instrumental, elencamos como objetivo principal deste estudo demonstrar algumas possíveis contribuições da Análise do Discurso para o ensino de leitura, propondo como entrada no texto a noção de interdiscurso.

Nesta seção, analisaremos dois textos cujo conteúdo temático apresenta uma intertextualidade marcada com o conto Cinderela. A escolha desse material deu-se por duas razões: 1. Textos físicos que apresentassem a tríade dialogismo, intertextualidade e interdiscurso. Ser um texto físico foi necessário porque, se pensarmos na dificuldade que muitas escolas têm de acesso à internet em suas aulas, a utilização de um texto deste tipo não seria um impeditivo para que a aula ocorresse. O texto poderia ser apresentado em slides ou, em não sendo possível, o professor poderia fazer uma cópia em tamanho ampliado do texto para que toda a sala pudesse ver melhor o material. 2. Textos que abordassem uma temática social relevante para os alunos. Se pensarmos na questão histórica da desigualdade, seja ele social, racial ou de gênero, vemos que a temática do empoderamento feminino se faz cada vez mais necessária, uma vez que tal problema se constitui uma prática histórica e perpetuada em nossa sociedade. As meninas, desde sempre, são tidas como frágeis e submissas (BRASIL, 2013).

Conforme Fiorin (2012), a intertextualidade pressupõe logicamente uma interdiscursividade, portanto, os textos em questão também são atravessados pela interdiscursividade. O primeiro texto é um cartoon, de Alexandre Kitani, e o segundo texto é uma peça publicitária da marca $\mathrm{O}$ Boticário. Apesar de ambos apresentarem uma relação intertextual com o conto Cinderela e trazerem à tona posicionamentos advindos da formação discursiva do discurso feminista postos em relação com o discurso patriarcal, a 


\section{REVISTA $\boldsymbol{X}$}

relação interdiscursiva se configura a partir de perspectivas diversas.

Os contos de fadas trazem para o leitor ou ouvinte ensinamentos sobre as normas de conduta que devem ser seguidas por determinados atores sociais, bem como as que são condenadas, dependendo da posição que se ocupa em determinada sociedade. É importante ressaltar que as tradições e os valores que estão sedimentados historicamente na sociedade não se referem a características herdadas por condições biológicas, sendo construídos e reconstruídos historicamente de acordo com os interesses sociais, conforme defendido por Simone de Beauvoir, ninguém nasce mulher, torna-se mulher. Nenhum destino biológico, psíquico, econômico define a forma que a fêmea humana assume no seio da sociedade (...) (BEAUVOIR, 1967, p. 9).

O conto da Cinderela, texto 1 , que deu origem aos textos em análise, apresenta a doçura, o decoro, o amor, a formosura e a obediência como virtudes que devem ser cultivadas pelas mulheres. Os dois textos em análise rompem com esse modelo de mulher: o primeiro apresenta uma perspectiva de ruptura com os posicionamentos advindos da formação discursiva patriarcal, e o segundo apresenta um posicionamento de relativismo. Vejamos o primeiro texto logo abaixo:

\section{Texto 1:}

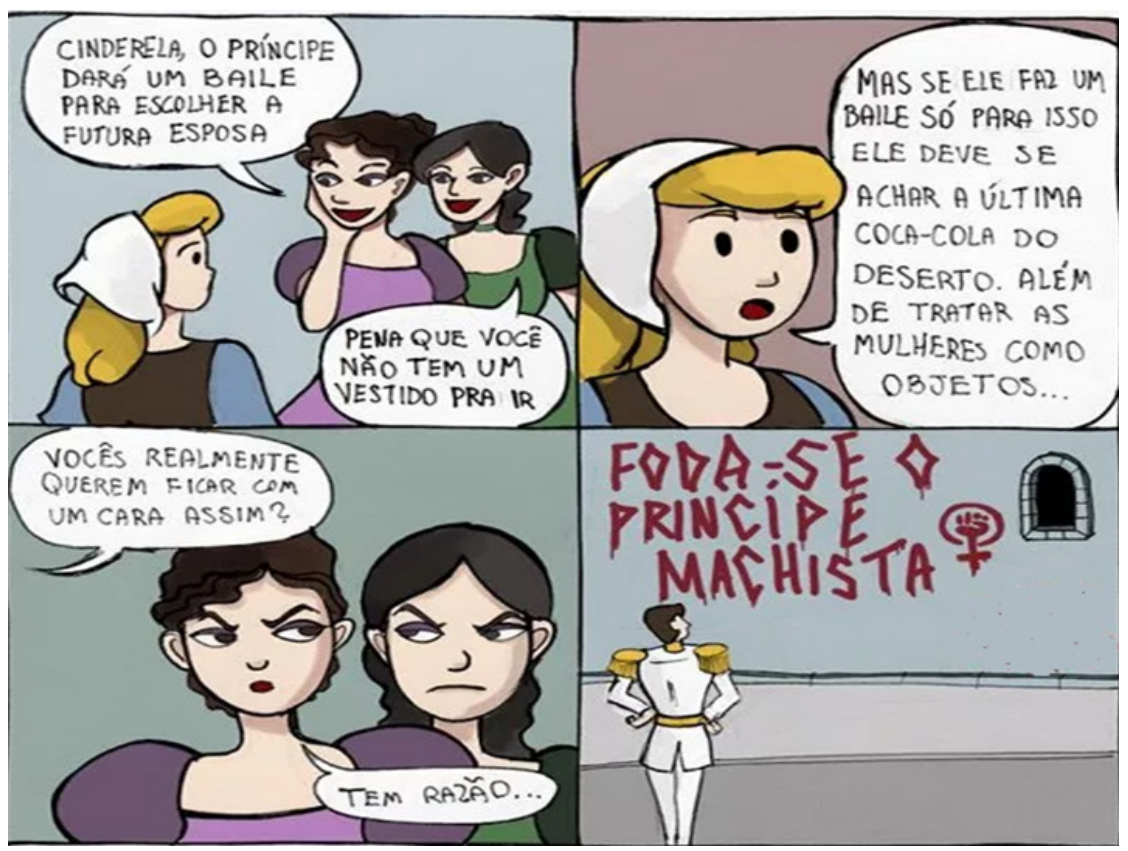

Fonte: $<$ https://64.media.tumblr.com/tumblr_mb4k2qquXE1rb3qj0o1_1280.jpg>. Acesso em: 20 fev. 2020. 
Conforme pode-se verificar, o cartoon em questão é uma adaptação do conto da Cinderela, traz traços quanto ao seu conteúdo temático que faz nos remeter ao conto desde o primeiro quadro, e o autor, logo no início, já situa a personagem homônima ao conto. Além disso, ele insere no cartoon duas personagens que, apesar de não terem sido nomeadas, cumprem a função das irmãs malvadas da heroína que, na história original, sempre procuram humilhar e diminuir a irmã mais velha pela sua condição. Outro traço intertextual marcante é o fato de o príncipe dar um baile convocando todas as moças do reino para que ele pudesse escolher a sua futura esposa.

O texto sob análise coloca em oposição os posicionamentos advindos da formação discursiva patriarcal, a qual emprega que as mulheres devem ser esposas, boas donas de casa e polidas e a formação discursiva feminista, a qual emprega que as mulheres devem ser livres, independentes, detentoras das suas vontades, tendo os mesmos direitos que os homens perante a sociedade.

No primeiro quadro, podemos observar que as duas personagens têm a intenção de rivalizar e de abalar a autoestima da personagem Cinderela, já que esta não teria condições de se apresentar com um belo vestido no baile, estando, por isso, fora da disputa pelo coração do príncipe encantado. Há um posicionamento, dentro da ideologia patriarcal, de situar as mulheres como desunidas, invejosas e sorrateiras, tendo esta prática discursiva o intuito de alimentar e justificar a rivalidade feminina como um arquétipo natural e inquestionável à condição das mulheres, sendo um dos ensinamentos trazidos pelo texto fonte a partir da relação de rivalidade estabelecida entre a Cinderela e as irmãs.

Já no segundo e no terceiro quadro, percebemos uma ruptura com esse posicionamento a partir do questionamento inserido por Cinderela quanto ao fato do baile representar uma prática de objetificação das mulheres, expondo-as à situação vexatória de serem colocadas à disposição de um monarca para que este, de acordo com a sua vontade, escolhesse quem seria a sua esposa. Diferente da história original, no texto em análise há uma ruptura com o discurso patriarcal, pois este, ao ser posto em relação com as ideologias que constituem o discurso feminista, proporciona uma tomada de consciência por parte das mulheres que passam a questionar as intenções associadas ao baile, gerando a revolta.

No último quadro, o espírito da revolta se materializa na pichação deixada pelas 
mulheres nos muros do castelo. Nele podemos observar o príncipe sozinho e impotente onde se encontra a inscrição "Foda-se o príncipe machista" e, além da frase, há o desenho associado à luta coletiva das mulheres que passaram a se identificar como um grupo social oprimido pelas amarras do sistema patriarcal.

Nesse sentido, a relação de oposição entre os posicionamentos advindos das formações discursivas em que se encontram o discurso feminista e o discurso patriarcal no campo político é a própria atualização do processo de delimitação recíproca que os constitui. Assim, o discurso feminista se instaura na contramão dos posicionamentos específicos da formação discursiva em que se encontra o discurso patriarcal.

$\mathrm{O}$ patriarcado representa um pacto social entre homens que tem encontrado forte resistência do grupo que esse sistema deseja oprimir e explorar: as mulheres (PRÁ, 2013). Como o movimento da história tem nos demonstrado, sempre que há relações de dominação e exploração, há resistência, luta e conflitos, que se expressam, no caso do texto sob análise, pela sabotagem e pela união das mulheres em prol de uma luta. De acordo com Fiorin (2012), os discursos são considerados históricos pelo fato de serem dialógicos, sendo essa historicidade compreendida pelo movimento interdiscursivo que a constitui e é constituído por ela. É na percepção que perpassa os discursos dos outros a partir de reprovações, aprovações, polêmicas, adesões e recusas que se constitui essa historicidade.

As ideologias constituem um relevante elemento de reificação e de alienação, sendo agrupadas em formações ideológicas, as quais correspondem determinadas formações discursivas, sendo interiorizadas pelos indivíduos no decorrer da sua vida. $\mathrm{O}$ discurso considerado como um construto social é, primeiramente, o lugar de apropriação antes de ser o da criação, pois ele é o lugar de manifestação dessas formações ideológicas que se constroem a partir de relações interdiscursivas (FIORIN, 2007). No primeiro texto em análise, percebemos que a relação interdiscursiva entre as formações ideológicas atualizadas pelo discurso feminista e pelo discurso patriarcal se deu em uma perspectiva de ruptura.

A Formação Discursiva a qual o sujeito está circunscrito nos permite compreender que o discurso machista e patriarcalista não está apenas no que é linguístico, mas também repousa nas imagens, nesse caso de moças ingênuas e recatadas, nas cores discretas de 


\section{REVISTA $\boldsymbol{X}$}

suas roupas e nas letras grande e em vermelho que formam o texto escrito que protesta quanto à atitude do príncipe. Perceber essas marcas nada inocentes no texto deve ser algo desejado por aqueles que conduzem os leitores. Como estamos tratando de ensino, nesse caso, os alunos poderiam perceber todos os elementos do texto como um ponto de chegada e nunca de partida, certamente, o professor precisa conduzir o leitor a um caminho nada inocente nos sentidos do texto.

O texto 2 que analisaremos também traz esse jogo interdiscursivo. Entre as formações discursivas do feminismo e do patriarcado, no entanto, ele se dá em uma perspectiva de relativização do discurso patriarcal a partir do discurso publicitário. Vejamos o texto abaixo:

\section{Texto 2:}

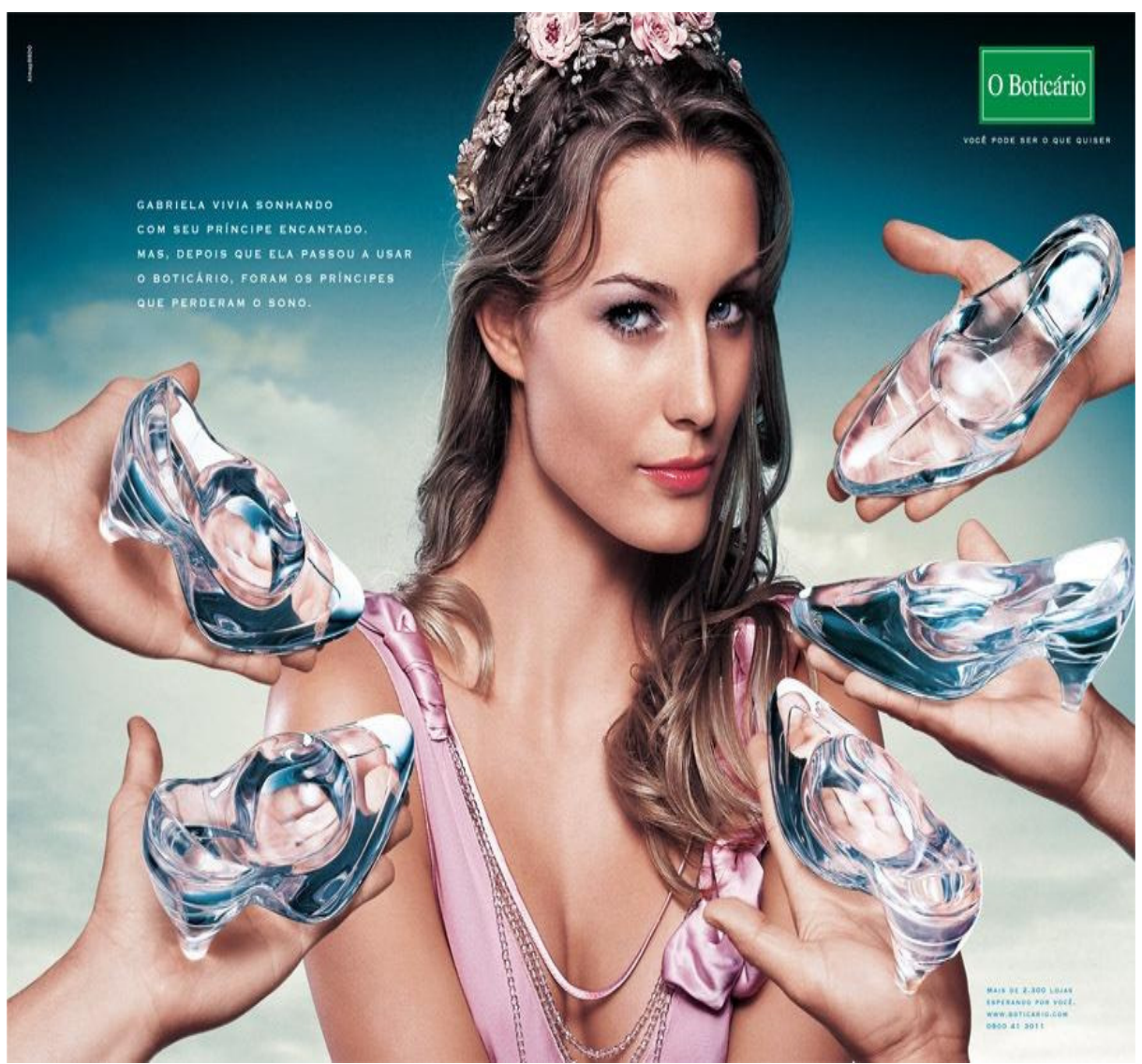

Fonte: <https://creativitate2013.files.wordpress.com/2013/03/960x720_287.jpg>. Acesso em: 17 fev. 2020. 
O texto em questão é uma peça publicitária da marca O Boticário que está inserida em uma série cujo caráter intertextual se dá a partir de semelhanças com alguns contos de fada. Nessa série, a marca vende um conceito: as mulheres que consomem a sua marca têm maior poder para seduzir os homens. No texto em questão, a relação intertextual também se dá com o conto da Cinderela, pois, na imagem, podemos ver vários homens oferecendo um sapatinho de cristal que, na história original, é o instrumento utilizado pelo príncipe para reconhecer a amada.

O texto da peça diz: Gabriela vivia sonhando com seu príncipe encantado. Mas, depois que ela começou a usar O Boticário, foram os príncipes que perderam o sono. Percebemos que há um distanciamento do conto original, pois na peça publicitária a mulher passa a ter o poder de escolher o seu príncipe encantado, caso ela consuma os produtos da marca. O texto apresenta relação interdirscursiva entre as formações ideológicas do discurso feminista e do discurso patriarcal, no entanto, diferentemente do texto anteriormente analisado, essa relação se dá por meio da relativização do discurso patriarcal através da sedução para o consumo, inerente ao discurso publicitário, pois a figura da mulher ainda está associada a de um homem não a considerando como um ser autônomo, pois esta, mesmo agora tendo o poder de escolher, ainda está à procura de um príncipe encantado.

De acordo com Saffioti (2004), no patriarcado, implantou-se uma hierarquia entre homens e mulheres, com primazia da figura masculina. A partir dos valores dessa formação ideológica, foi inserida a ideia de que o homem é um ser essencial, já a mulher não o é, sendo o primeiro considerado sujeito à mulher, por sua vez, é o outro, adquirindo um maior valor perante a sociedade se estiver em uma relação romântica com um homem, relegando a mulher à exploração-dominação masculina.

As formações ideológicas que sustentam as bases do patriarcado foram construídas especialmente para justificar uma estrutura de poder que situa as mulheres muito abaixo dos homens em todas as áreas da convivência humana, situando a primazia masculina como o preceito natural, não como um conceito de ordem social que, por sua vez, traz implicações políticas. O objetivo das feministas consiste em transformar a sociedade, eliminando as desigualdades e as injustiças. Essa ruptura também se dá no campo discursivo, que é também espaço de disputas ideológicas. 
Os dois textos que acabamos de analisar apresentam relações interdiscursivas que põem em relação o discurso feminista e o discurso patriarcal, no entanto, verificamos que esta relação ocorre a partir de perspectivas diferentes, pois o primeiro apresenta um teor de ruptura com o patriarcado e primazia do feminismo, ao passo que o segundo já ocorre a partir de uma relação de relativização, pois, apesar de considerar que a mulher tem poder de escolha, a figura feminina ainda está associada a de um homem.

Em se tratando da relação da $\mathrm{AD}$ com o ensino de língua portuguesa, foco deste artigo, é importante que o professor desenvolva estratégias para demonstrar as várias nuances que as relações interdiscursivas interpelam, uma vez que as ideologias constroem a nossa visão de mundo, não se relacionam de maneira única e estanque, instauram práticas de ruptura, relativização, aliança e legitimação, a depender do posicionamento adotado. Na próxima seção, apresentaremos algumas sugestões de questões de leitura para serem lançadas em sala de aula a partir do viés discursivo.

\section{ALGUMAS QUESTÕeS PARA A AULA DE LEITURA}

Considerando a exposição feita por Braggio (1992) sobre as teorias e os modelos de leitura, pautamo-nos na concepção sociopsicolinguística para construir as questões de leitura com foco no conceito de interdiscurso. Exporemos, brevemente, os principais preceitos dessa concepção de leitura nas próximas linhas e, posteriormente, apresentaremos as questões construídas.

A concepção sociopsicolinguística de leitura tem como foco a interação do leitor com o autor do texto, considerando a relevância da intervenção formativa mediada pelo professor para a formação de leitores. O leitor é considerado de maneira ativa, mobilizando seus conhecimentos previamente adquiridos e os conhecimentos trazidos no texto para construir uma nova significação. De acordo com essa concepção, em um primeiro momento, cada leitor constrói os significados do texto, mas, posteriormente, com a intervenção formativa do professor, essa compreensão é socializada, provocando um desequilíbrio, uma vez que a compreensão é reconstruída coletivamente, construindo um novo significado resultante desse novo evento.

Nessa perspectiva, o professor assume um papel fundamental, pois ele é o mediador que contribui para que a compreensão aconteça coletivamente e os significados 
sejam reconstruídos. Para que o professor alcance o estatuto de formador de leitores críticos, é necessário que ele tenha acesso aos objetos teóricos dos estudos da linguagem e realize um processo de transposição didática dessas teorias para o trabalho em sala de aula.

O nosso trabalho trata, especificamente, de algumas possíveis contribuições que os aportes teóricos da $\mathrm{AD}$ podem trazer para o ensino de leitura, mais especificamente o conceito de interdiscurso. Nas próximas linhas, apontaremos algumas sugestões de entradas no texto a partir dessa categoria. Não temos a intenção de esgotar as possibilidades interpretativas dos textos ou de engessar a discussão em torno das possíveis transposições didáticas que podem ser realizadas a partir da AD. Temos o intuito de mostrar algumas coordenadas que podem direcionar o trabalho com o texto em uma perspectiva discursiva. Vejamos, nas próximas linhas, a trajetória de aula de leitura que traçamos. Essa trajetória tem por base o conceito de estratégias de leitura proposto por Solé (1998). Para a autora, a formação de um leitor precisa ter como objetivo o desenvolvimento de habilidades de compreensão antes, durante e depois da leitura de um texto. O leitor precisa ser um estrategista, um planejador para compreender o texto.

A primeira etapa consiste em uma pré-leitura, cujo objetivo é ativar os conhecimentos prévios dos alunos. Nesse momento, o aluno ainda não deve ter lido o texto, pois essa etapa deve estimular a formulação de hipóteses por parte dos alunos que serão confirmadas, ou não, na sequência da atividade de leitura. Nos textos específicos que estamos trabalhando, seria interessante que se lançasse para a turma questões relacionadas aos contos de fada como, por exemplo:
a) Citem exemplos de contos de fadas que vocês conhecem?
b) Quais os assuntos que eles, normalmente, têm em comum?
c) Vocês conhecem alguma história atual que tenha elementos similares aos contos de fadas, mas que apresentam também diferenças?
d) Quais seriam essas diferenças e essas semelhanças?

Depois de realizada essa etapa, é necessário que os alunos entrem em contato com o texto, realizando uma leitura com objetivos. Após ter sido realizada a leitura, é necessário que o professor proponha questões que tenham o objetivo de explorar o aspecto selecionado. Em se tratando do conceito de interdiscurso, entrada linguística selecionada 
por nós, que tem o objetivo de demonstrar a relação necessária e recíproca entre os diversos discursos que permeiam a sociedade, é necessário que o professor lance questões que façam com que os alunos reconheçam as formações discursivas que estão postas em relação nos textos, no caso a feminista e a patriarcal, e entendam a diferença de posicionamento construída nos dois textos.

Como sugestões de questão, teríamos:

a) Quais as diferenças entre o enredo do texto original e o enredo do primeiro e do segundo texto?

b) No segundo quadro do cartoon, o "mas" inaugura um argumento diferente do contido no primeiro quadro. Sintetizem essas novas informações.

c) Depois de inseridos esses novos argumentos nos dois textos, como as heroínas das duas histórias passam a ser percebidas? Em que aspectos elas se distanciam da Cinderela do conto original?

d) Ao se verificar os dois textos em questão, que diferenças vocês percebem entre as figuras femininas?

e) Qual a diferença de posicionamento entre o texto 1 e o texto 2?

A terceira etapa consiste em ressignificar as ideias apresentadas nos textos para a ampliação de novos significados e conhecimentos. Nessa etapa, o leitor deve defender o seu ponto de vista diante do texto lido, tomando os textos analisados como um ponto de partida para reflexão e aprofundamentos das ideias.

Como sugestão para essa etapa, temos as seguintes questões:

a) No último quadro do texto 1, percebemos uma fonte e um suporte diferentes dos utilizados tradicionalmente no gênero cartoon. Na sua opinião, qual o efeito de sentido produzido pela escolha desses recursos expressivos?

b) Há dois pontos de vistas defendidos nos textos. Ambos os pontos de vista têm relação com o desejo do príncipe e com a compreensão de Cinderela. Sintetize esses dois pontos de vista e relacione com o que você percebe na sociedade atual.

c) Percebemos que há dois modelos de mulheres apresentados nos dois textos. Quais as implicações que esses dois modelos de mulheres trazem para a sociedade, levando em consideração as suas diferenças e semelhanças?

Ao tomarmos os aportes teóricos da AD para a análise dos textos, podemos ter acesso às formações discursivas que dizem respeito à existência histórica do enunciado, 
tornando possível o acesso por parte dos educandos aos posicionamentos políticos e ideológicos que não são construídos de forma individual, uma vez que estão organizados em formações que mantêm entre si relações de antagonismo, de aliança, de relativismo ou de dominação.

Trazer a noção de interdiscurso para o âmbito do ensino de leitura nas escolas pode ser bastante produtivo, no sentido de proporcionar aos alunos uma reflexão acerca dos fatores sócio-históricos e ideológicos que constituem os sentidos do texto, trazendo os embates e as disputas que se cristalizam no interior do interdiscurso. Entendemos que é na tensão motivada pela disputa de sentidos produzidos entre formações discursivas distintas que o texto vai sendo impregnado de índices valorativos contraditórios e, por isso mesmo, ele materializa traços da luta ideológica e de classes.

\section{CONSIDERAÇÕES FINAIS}

Os conceitos advindos da análise do discurso, ao trazer pressupostos teóricos e dispositivos de análise que tratem da dimensão ideológica e conflituosa da linguagem materializada nos textos, podem contribuir fortemente para a formação de leitores críticos e autônomos, capazes de se valerem de mecanismos discursivos em prol do seu engajamento em práticas cidadãs.

Conforme já mencionamos, a língua, na perspectiva da análise do discurso, é considerada opaca e heterogênea, consequentemente, ela não é transparente e homogênea como aparenta ser nas atividades de leitura em situação escolar. Trouxemos as noções de interdiscurso como possível entrada no texto para acessar os efeitos de sentido que estão no nível da discursividade, demonstrando que na base dos processos discursivos, além da materialidade simbólica, há também uma materialidade histórica, formada pelas relações sociais de uma determinada formação social, em meio as quais (e para as quais) os sujeitos históricos trabalham a formulação dos seus dizeres, provocando agitações nas filiações dos sentidos e, também, produzindo uma práxis discursiva que almeje mudanças.

Para, entretanto, não cairmos numa concepção estática do social e de seus conflitos, é igualmente importante que o professor demonstre que tais desigualdades e assimetrias não são inexoráveis, eternas e inquestionáveis, e que sobre elas instauraram-se práticas de ruptura, tensionamento, reacomodação e alteração na ordem instituída destes 
lugares e poderes pré-estabelecidos, herdados. Assim, ao pensar o discurso, esse instrumento fundamental da prática política, é pensar como a história se inscreve na linguagem.

\section{REFERÊNCIAS}

BAKHTIN, M. Estética da criação verbal. São Paulo: Martins Fontes, 1992.

BEAUVOIR, S. L. E. M B. O segundo sexo II - a experiência vivida. São Paulo: Difusão Europeia do Livro, 1967.

BRASIL. Secretaria de Políticas para as Mulheres - SPM. Plano Nacional de Políticas para as mulheres - 2013-2015. Brasília, 2013. Disponível em: $<$ https://oig.cepal.org/sites/default/files/brasil_2013_pnpm.pdf $>$. Acesso em: 10 ago. 2020 .

BRAGGIO, S. L. B. Leitura e alfabetização: da concepção mecanicista à sociopsicolingüística. Porto Alegre, Artes Médicas, 1992.

CHARAUDEAU, P.; MAINGUENEAU, D. Dicionário de Análise do Discurso. 2.ed. São Paulo: Contexto, 2008.

CORACINI, M. J. F. R. (org.). O jogo discursivo na aula de leitura: língua materna e lingua estrangeira. Campinas: Pontes Editores, 1995.

FERREIRA, M. C. L. O quadro atual da Análise de Discurso no Brasil. Revista do Programa de Pós-Graduação em Letras da Universidade Federal de Santa Maria. Santa Maria, n.27, p.39-46. Disponível em: https://periodicos.ufsm.br/letras/article/view/11896. Acesso em: 12 ago. 2020.

FIORIN, J. L. Linguagem e ideologia. São Paulo: Ática, 2007.

Da necessidade da distinção entre texto e discurso. In: BRAIT, B.; SOUZA-ESILVA, M. C. Texto ou discurso? São Paulo: Contexto, 2012, p. 145-165.

FOUCAULT, M. A ordem do discurso. São Paulo: Loyola, 1996.

MAINGUENEAU, D. Novas tendências em análise do discurso. Campinas: Pontes Editora da UNICAMP, 1997.

MARCUSCHI, L. A. Produção de texto, análise de gêneros e compreensão. São Paulo: Parábola Editorial, 2008.

ORLANDI, E. P. Análise do discurso: princípios e procedimentos. 6.ed. Campinas, SP: 
Pontes, 2005.

PÊCHEUX, M. Semântica e discurso: uma crítica à afirmação do óbvio. Campinas, SP: Editora da Unicamp, 1998.

O discurso: estrutura ou acontecimento. Campinas, SP: Pontes, 2006.

PRÁ, J. R. Estereótipos e ideologias de gênero entre a juventude brasileira. Revista Feminismos, v.1, n.3, 2013, p.1-23. Disponível em: $<$ https://pdfs.semanticscholar.org/6455/f8cb4b6d25050b5487f58ce417c4ef357708.pdf>. Acesso em: 12 ago. 2020.

SAFFIOTI, H. I. B. Gênero, Patriarcado, Violência. São Paulo: Fundação Perseu Abramo, 2004

SOLÉ, I. Estratégias de leitura. Porto Alegre: Artmed, 1998.

Recebido em: 18 mai. 2020. Aceito em: 24 ago. 2020. 